\title{
Regiões organizadoras nucleolares argirofílicas no sarcoma sinovial
}

\author{
Argyrophilic nucleolar organizer regions in synovial sarcoma
}

Flávio de Oliveira Lima'; Regina Maria Catarino²; Celina Tizuko Fujiyama Oshima ${ }^{3}$; Marco Túllio de Assis Figueiredo ${ }^{4}$

\section{unitermos resumo} pela transcrição do RNA ribossômico, de $18 \mathrm{~S}$ e $28 \mathrm{~S}$, situados no nucléolo da célula. Por possuírem reatividade com a prata são chamadas de AgNORs. O presente estudo investigou a correlação entre o número de AgNORs por núcleo e o prognóstico em dez sarcomas sinoviais diagnosticados no Hospital A. C. Camargo, entre 1972 e 1986, com informações confiáveis de seguimento clínico. A análise dos resultados não revelou correlação entre as variáveis estudadas, mostrando que o número de casos investigados e sua homogeneidade morfológica não permitem conclusões acerca do valor prognóstico dos AgNORs nos sarcomas sinoviais. Outrossim, o método se revelou barato, rápido e de aplicação simples para todo e qualquer serviço de patologia cirúrgica, podendo ser útil para avaliação da proliferação celular na rotina de laboratórios de pequeno porte.

The argyrophilic nucleolar organizing regions (AgNOR) are regions of the DNA that contain the sequences for the synthesis of the ribosomic RNA. They are localized in the short arms of human acrocentric chromosomes and they are indicators of cellular proliferation and ribosomal activity. The present study investigated the correlation between the number of AgNOR per nucleus and the prognosis of ten synovial sarcomas diagnosed at Hospital A.C. Camargo from 1972 to 1986. The analysis of the results did not show a statistical correlation with the different variables. The small number of patients in this series and their morphological uniformity do not allow reaching a conclusion regarding the prognostic value of the AgNOR in synovial sarcoma. This method is inexpensive, fast and simple, and can be used in any surgical pathology laboratory. This method can be useful in the routine evaluation of cellular proliferation in small pathology laboratories.

\section{Introdução}

O termo regiões organizadoras nucleolares, ou NORs (do inglês nucleolar organizer regions), é utilizado para descrever regiões constituídas de fragmentos de cromossomos em torno das quais se formam os nucléolos no final da mitose. Essas regiões correspondem a alças do DNA contendo genes responsáveis pela transcrição do RNA ribossômico, de 18S e 28S, situados no nucléolo da célula ${ }^{(8,17)}$, e por possuírem reatividade com a prata foram chamadas de AgNORs.

No homem, essas regiões correspondem a constrições secundárias e se localizam no braço curto dos cromossomos acrocêntricos 13, 14, 15, 21 e 22. Como as NORs estão associadas aos cromossomos acrocêntricos

\footnotetext{
1. Mestre em Anatomia Patológica pelo Departamento de Patologia da Universidade Federal de São Paulo (UNIFESP/EPM).

2. Doutora em Ciências pela Disciplina de Castroenterologia da UNIFESP/EPM; pesquisadora do Instituto Adolfo Lutz.

3. Doutora em Ciências pela Disciplina de Gastroenterologia da UNIFESP/EPM; pesquisadora da Fundação Oncocentro de São Paulo.

4. Doutor em Anatomia Patológica pelo Departamento de Patologia da UNIFESP/EPM; professor aposentado.

Tese de mestrado apresentada ao Departamento de Patologia da UNIFESP/EPM em 1996.
} 
pensou-se, inicialmente, que estivessem relacionadas com a ploidia. Entretanto, estudos correlacionando as NORs e as variáveis histológicas convencionais ${ }^{(21)}$, o estudo do núcleo interfásico através dos métodos citogenéticos ${ }^{(9)}$, a cinética celular( ${ }^{(3)}$, a imunorreatividade do $\mathrm{Ki}-67^{(7)}$ e a citometria de fluxo $^{(1)}$ sugerem que as AgNORs estejam associadas principalmente à proliferação celular.

Ploton et al. ${ }^{(18)}$ padronizaram uma versão modificada da técnica de impregnação pela prata, realizando a reação em uma só fase, à temperatura ambiente $\left(20^{\circ} \mathrm{C}\right)$ e penumbra. A modificação permitiu que essas regiões fossem vistas em cortes de tecido fixados em formalina e incluídos em parafina tanto em células em metáfase como em interfase.

O sarcoma sinovial é um tumor raro de partes moles que ocorre com mais freqüência em adultos jovens, sendo que $60 \%$ a $70 \%$ dos casos comprometem a extremidade inferior, em particular as extremidades do joelho. Outros locais de ocorrência incluem cabeça e pescoço, tronco, parede abdominal, coração, mediastino e cavidade pleural. Respondem por cerca de $10 \%$ de todos os sarcomas de partes moles e pelo quarto lugar entre os sarcomas mais comuns $^{(5)}$.

Enzinger e Weiss ${ }^{(5)}$ classificaram os sarcomas sinoviais em quatro grupos com base na sua morfologia microscópica: bifásico, monofásico fusocelular, monofásico epitelial e pouco diferenciado. O sarcoma bifásico é facilmente reconhecido pela coexistência de componentes distintos de células epiteliais e fusiformes, com estruturas pseudoglandulares. No entanto, o tipo monofásico, devido ao seu crescimento semelhante a outros sarcomas, pode representar maior dificuldade ao diagnóstico histopatológico. O padrão monofásico fusocelular pode ser confundido com outros sarcomas, como o fibrossarcoma, o leiomiossarcoma e o tumor maligno da bainha do nervo periférico.

O diagnóstico é difícil devido a sua baixa ocorrência e devido à semelhança de achados histológicos e morfológicos entre lesões primárias e metastáticas.

Em geral, o prognóstico está baseado na combinação do grau histológico e fatores clínicos. Três critérios são considerados: diferenciação, necrose e o índice de proliferação celular dado pelo uso do anticorpo monoclonal MIB-1.

Informações sobre os fatores prognósticos são essenciais para o estabelecimento de terapias adequadas. Em vista disso, nosso estudo teve como objetivo analisar a proliferação celular através das contagens das AgNORs no tecido de sarcoma sinovial e a possível relação com a sobrevida dos pacientes.

\section{Material e métodos}

\section{Casuística}

Foram analisados, retrospectivamente, dez casos de sarcoma sinovial utilizando blocos em parafina obtidos dos arquivos do Departamento de Anatomia Patológica do Hospital A. C. Camargo de São Paulo, atendidos entre 1972 e 1986. Esse período foi escolhido porque a partir de 1972 os sarcomas passaram a ser rotineiramente submetidos a uma metodologia de estudo histológico preconizado por Figueiredo ${ }^{(6)}$, a qual possibilitou maior segurança no diagnóstico histogenético. Além disso, o ano de 1986 permitiu um seguimento clínico de cinco anos até 1991. Nesse período foram registrados 28 casos de sarcoma sinovial, porém 18 foram descartados do estudo por não apresentarem blocos em bom estado ou informações confiáveis de seguimento clínico.

\section{Métodos}

A coloração das AgNORs foi realizada em cortes histológicos com $3 \mu \mathrm{m}$ de espessura. A solução de incubação foi preparada dissolvendo-se $0,2 \mathrm{~g}$ de gelatina em $10 \mathrm{ml}$ de água destilada e deionizada a $60^{\circ} \mathrm{C}$, acrescentando-se $100 \mu \lambda$ de ácido fórmico à solução fria. Essa solução foi misturada com uma solução de nitrato de prata $50 \%$ (modificado de Ploton et al.) $)^{(18)}$, na proporção de 1:2. A solução resultante foi gotejada sobre o corte histológico, que foi incubado por 45 minutos a $37^{\circ} \mathrm{C}$, em câmara escura. Após esse tempo as lâminas foram lavadas em água deionizada, desidratadas e montadas em Entellan.

Água destilada e deionizada foi utilizada para o preparo das soluções, reações e lavagens, a fim de reduzir-se a coloração de fundo. Os cortes histológicos não foram contracorados e, como resultado, obtivemos os cortes corados em tom amarelo-acastanhado claro e as AgNORs como pontos negros ou castanho-escuros.

A análise quantitativa das AgNORs foi realizada por microscopia óptica, onde um total de cem núcleos de células neoplásicas dos componentes epitelióide e mesenquimal foram analisados em separado (200 núcleos por caso) com aumento de mil vezes num microscópio Nikon.

Foram selecionadas áreas do tumor com maior número de pontos corados, não superpostos, sendo realizada uma busca extensa em grandes áreas para que não houvesse repetição dos campos observados.

A escala de coloração para visualização dos pontos das AgNORs foi selecionada individualmente, após um aumento 
do contraste, até o momento em que os pontos das AgNORs fossem facilmente identificados como pontos negros ou castanho-escuros dentro do núcleo. Esses pontos podiam se apresentar isolados e arredondados, aglomerados formando cachos ou dispersos pelo núcleo.

O coeficiente de correlação de Spearman foi utilizado na análise dos resultados.

\section{Resultados}

Dos dez sarcomas sinoviais analisados, seis eram de mulheres e quatro de homens, e a idade média foi de 26 anos. Cinco apresentaram lesão até $5 \mathrm{~cm}$; quatro, entre 5 e $10 \mathrm{~cm}$; e um, entre 10 e $15 \mathrm{~cm}$. Seis foram de membro inferior (pé, joelho e coxa) e quatro, de membro superior (mão, braço e ombro). Cinco pacientes evoluíram com recidiva e metástase, três com recidiva, e dois estavam livres da doença. Os sítios de metástases foram pulmão (três pacientes), pulmão e linfonodos (um paciente) e linfonodos, ossos e sistema nervoso central (um paciente).

A sobrevida média dos pacientes foi de 66,5 meses, com mediana de 58,5 e desvio padrão de 45,63 meses. Ao final do estudo dois pacientes estavam vivos com doença, três estavam vivos livres da doença e houve cinco óbitos em decorrência da doença. As terapias utilizadas foram cirurgia e quimioterapia (dois doentes), cirurgia e radioterapia (um doente) e cirurgia, químio e radioterapia (sete doentes).
A Tabela apresenta a média, o erro padrão, a mediana das contagens das AgNORs nos elementos epitelióide e mesenquimal fusiforme e a sobrevida em meses dos pacientes com sarcoma sinovial.

Não foi observada correlação entre a sobrevida dos pacientes e o número de AgNORs no componente epitelióide $(p=0,285)$, entre a sobrevida e o número de AgNORs no componente mesenquimal $(p=0,54)$ e entre a sobrevida e a contagem geral de AgNOR total $(p=0,46)$.

A fotomicrografia da Figura 1A mostra um sarcoma sinovial com elemento epitelióide com aspecto papilífero, corado por hematoxilina e eosina (HE); e a Figura 1B, o mesmo sarcoma sinovial corado pela prata. Podemos observar a AgNOR intranuclear castanha e deposição inespecífica da prata. Na Figura 1C observamos o sarcoma sinovial com elemento mesenquimal fusocelular, $\mathrm{HE}$; e na Figura 1D, agregados intranucleares de AgNOR passíveis de individualização no elemento mesenquimal fusocelular. A Figura 1E apresenta um sarcoma sinovial com elemento epitelióide sólido, HE; e a Figura 1F, AgNOR intranuclear no elemento epitelióide sólido.

\section{Discussão}

O interesse na suplementação dos métodos tradicionais usados para avaliar o prognóstico do câncer tem levado ao desenvolvimento de diferentes tipos de marcadores tumo-

Tabela 1

Correlação entre contagens de AgNoRs (pontos por núcleo) nos elementos mesenquimal e epiteliöide, contagem total e sobrevida (em meses) dos pacientes portadores de sarcoma sinovial

\begin{tabular}{ccccc}
\hline & Elemento epitelióide & Elemento mesenquimal & AgNOR total & Sobrevida (meses) \\
Caso 1 & 6,51 & 6,1 & 6,3 & 44 \\
Caso 2 & 6,27 & 4,68 & 5,37 & 37 \\
Caso 3 & 5,56 & 5,22 & 5,39 & 82 \\
Caso 4 & 9,19 & 12,14 & 10,66 & 19 \\
Caso 5 & 6,2 & 6,44 & 6,32 & 20 \\
Caso 6 & 6,26 & 4,91 & 5,58 & 36 \\
Caso 7 & 4,35 & 4,37 & 4,36 & 103 \\
Caso 8 & 8,06 & 6,78 & 7,42 & 73 \\
Caso 9 & 7,52 & 9,02 & 8,27 & 167 \\
Caso 10 & 5,57 & 5,79 & 5,6 & 84 \\
Média & 6,549 & 6,545 & 6,547 & 66,5 \\
Mediana & 6,26 & 5,94 & 5,99 & 58,5 \\
Desvio padrão & 1,38 & 2,37 & 1,81 & 45,63 \\
\hline
\end{tabular}




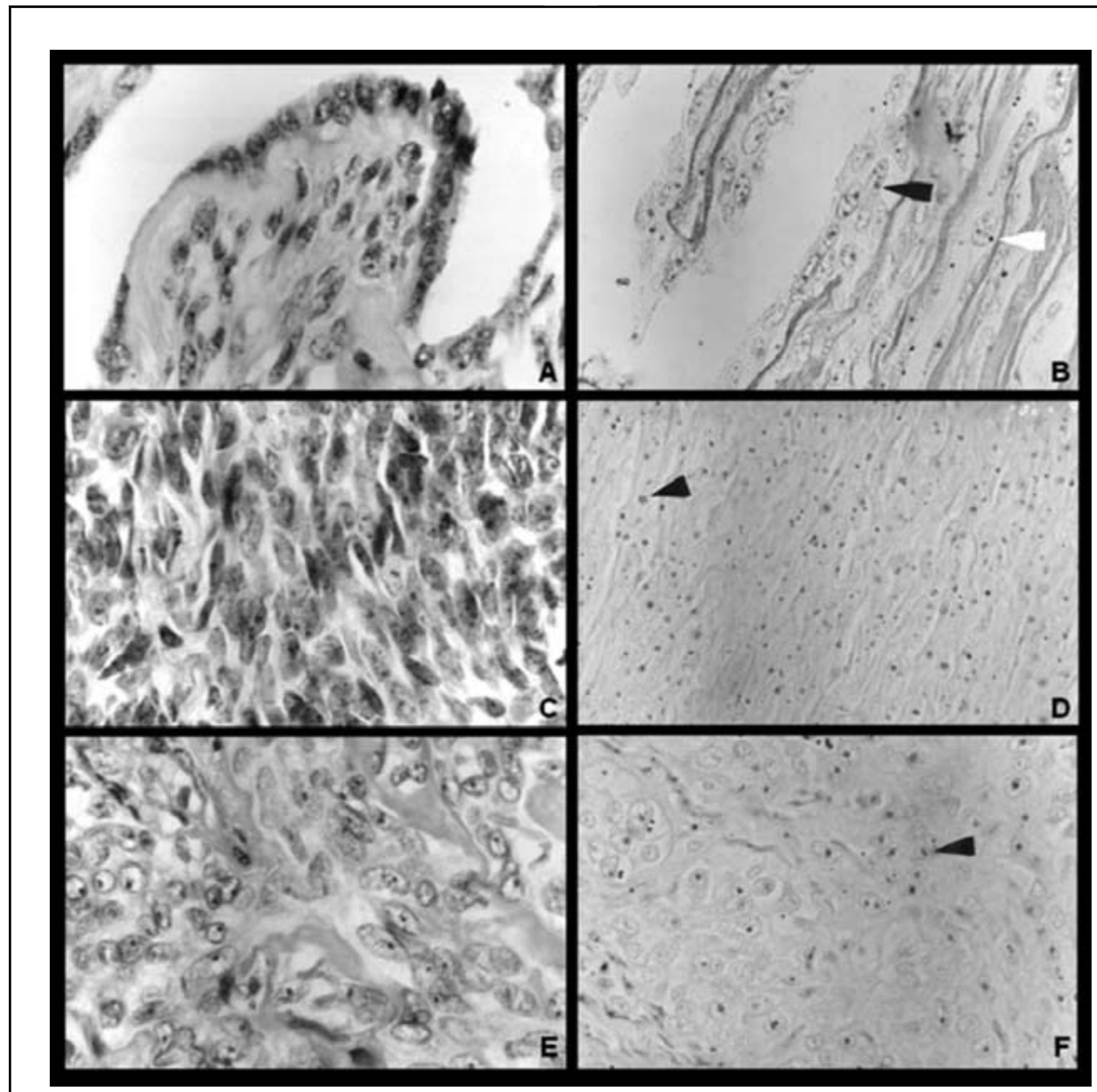

Figura 1 - A fotomicrografia da figura $1 \mathrm{~A}$ mostra um sarcoma sinovial com elemento epitelióide com aspecto papilifero, corado pela hematoxilina-eosina, e na figura $1 \mathrm{~B}$ o mesmo sarcoma sinovial corado pela prata. Podemos observar o AgNOR intranuclear castanho e deposição inespecífica da prata. Na figura 1C observamos o sarcoma sinovial com elemento mesenquimal fusocelular, $\mathrm{HE}$, e na figura 1D, agregados intranucleares de AgNOR passíveis de individualização no elemento mesenquimal fusocelular. A figura $1 E$ apresenta um sarcomasinovial com elemento epitelióide sólido, HE, e a figura 1F AgNOR intranuclear no elemento epitelióide sólido

rais. A descoberta desses marcadores permitiria discriminar com maior clareza pacientes que seriam favorecidos com cirurgia, cirurgia associada a quimioterapia, tratamentos mais agressivos ou protocolos experimentais.

Crocker et al. (2) sugeriram que a técnica de AgNOR teria utilidade prática em patologia, para demonstração de potencial neoplásico e para avaliação de prognóstico e agressividade de neoplasias malignas. Em vista disso, a quantificação das AgNORs foi introduzida em histopatologia como marcador da atividade celular e nucleolar ${ }^{(15)}$.
A análise da expressão das AgNORs pode ser realizada pela contagem e pelo padrão de distribuição dos pontos negros dentro do núcleo na microscopia óptica, pela medida de sua área por análise de imagem ou pelo cálculo de coeficientes que relacionam esses dois critérios ${ }^{(14)}$.

As AgNORs variam em tamanho e forma, de acordo com a transcrição nucleolar, e estão intimamente relacionadas ao ciclo celular, à proliferação e à ploidia ${ }^{(19)}$. Porém, não se relacionam com o número de cromossomos e o conteúdo de $\mathrm{DNA}^{(4)}$. Além disso, têm sido usadas para diferenciar processos benignos e malignos em alguns tumores ${ }^{(16)}$. 
Observamos que as AgNORs se apresentaram como pontos intranucleares castanho-escuros isolados e grandes, ou pequenos e numerosos ou aglomerados. Evitamos a análise em regiões com representações incompletas do núcleo e quando os pontos apareciam sobrepostos, de forma aglomerada, dificultando a visualização e a contagem.

Se considerarmos oito pontos negros por núcleo o limite entre grupos de alta e baixa contagem, como Kuratsu ${ }^{(12)}$, teremos somente dois tumores de alta contagem, um com 8,27 AgNORs por núcleo e outro com 10,66 AgNORs por núcleo. Se o limite for dez pontos por núcleo, teremos apenas um tumor com alta contagem. Por outro lado, se considerarmos as médias obtidas pelo mesmo grupo em outro estudo como menor que quatro ou maior ou igual a quatro, todos os nossos casos se encontram no segundo grupo ${ }^{(13)}$. Além disso, pacientes que tiveram número de AgNORs aumentados também tiveram prognósticos desfavoráveis. Índice de proliferação celular, medido pelo $\mathrm{Ki}-67$, é sugerido também como indicador de prognóstico em sarcoma sinovial (Y1Y2). A sobrevida média de nossos pacientes foi de 66 meses e a metade deles teve sobrevida maior que cinco anos.

O presente estudo considerou os sarcomas sinoviais de um período de 14 anos (1972-1986). Para obtenção de 25 sarcomas sinoviais, Rooser et al.(20) e Kuratsu et al.(12) contaram com informações de um período de 26 e 25 anos, respectivamente. Essas considerações explicam o pequeno número de casos por nós estudados e a falta de correlação estatística com a sobrevida.
São considerados fatores prognósticos para sarcoma sinovial: relação do índice mitótico, tamanho do tumor, idade, presença de áreas pouco diferenciadas, de áreas rabdóides e de áreas extensas de necrose. Além disso, alto índice de proliferação celular é considerado fator adverso para mortalidade relacionado à doença ${ }^{(1,3,7)}$. Cinco de nossos pacientes tinham tumores maiores que $5 \mathrm{~cm}$, enquanto somente um apresentava tumor maior que $10 \mathrm{~cm}$. Se utilizarmos a classificação morfológica inespecífica utilizada por Kuratsu et al. ${ }^{(12)}$ seis dos nossos casos seriam epitelióides e quatro, fusocelulares.

Alta relação de mitose aliada a um tumor maior relaciona-se com recorrência local e doença metastática. Em nosso estudo não foi avaliado o índice mitótico, porém cinco pacientes apresentavam recidiva e doença metastática. Três pacientes apresentavam somente recidiva e dois pacientes estavam livres da doença. Pulmão foi o sítio de metástase preferencial, seguido de pulmão e linfonodos e linfonodos, ossos e sistema nervoso central. Cinco pacientes tiveram a sobrevida maior que cinco anos.

A análise dos resultados não revelou correlação entre as variáveis estudadas, mostrando que o número de casos investigados e sua homogeneidade morfológica não permitem conclusões acerca do valor prognóstico das AgNORs nos sarcomas sinoviais.

Outrossim, o método se revelou barato, rápido e de aplicação simples para todo e qualquer serviço de patologia cirúrgica, podendo tornar-se útil para avaliação da proliferação celular na rotina diagnóstica.

\section{Referências}

I. CROCKER,J.; MACARTNEY,J. C.; SMITH, P.J. Correlation between DNA flow cytometric and nucleolar organizer region data in non-Hodgkin's lymphomas.J Pathol, v. I54, p. 151-6, 1988.

2. CROCKER, J; BOLDY, D. A. R.; EGAN, M. J. How should we count AgNORs? Proposals for a standardized approach. J Pathol, v. 158, p. 185-8, 1989.

3. DERENZINI, M. et al. Relationship between interphasic nucleolar organizer regions and growth rate in two neuroblastoma cell lines. Am J Pathol, v. I 34, n. 4, p. 925-32, 1989.

4. DERENZINIM, M.; THERÉ, D. AgNOR proteins as a parameter of the rapidity of cell proliferation. Zentralbl Pathol, v. 140, p. 7-10, 1994.

5. ENZINGER, F. M.;WEISS, S.W. Synovial sarcoma. In: ENZINGER, F. M.; WEISS, S. W., editors. Soft tissue tumors. 3 ed. St. Louis: CV Mosby, 1995. p. 757-86.

6. FIGUEIREDO, M.T.A. Soft tissue sarcoma: a routine for histological examination. Acta Oncol Bras, v. 7, p. 37-9, 1987.
7. HALL, P. A. et al. A comparison of nucleolar organizer region staining and Ki-67 immunostaining in non-Hodgkin's lymphoma. Histopathol, v. 12, p. 373-81, 1988.

8. HSU, T. C; SPIRITO, S. E; PARDUE, M. L. Distribution of $18+28 \mathrm{~S}$ ribosomal genes in mammalian genomes. Chromosoma, v. 53, p. 25-36, 1975.

9. JAN-MOHAMED, R. M. et al. The relationship between number of interphase NORs and NOR-bearing chromosomes in non-Hodgkin's lymphoma.J Pathol, v. I58, p. 3-7, 1989.

10. KAWAUCHI, S. Prognostic significance of apoptosis in synovial sarcoma: correlation with clinicopathologic parameters, cell proliferative activity, and expression of apoptosis-related proteins. Mod Pathol, v. I 3, n. 7, p. 755-65, 2000.

I I. KAWAUCHI, S. Low expression of p27 (Kipl), a cyclindependent kinase inhibitor, is a marker of poor prognosis in synovial sarcoma. Cancer, v. 91, n. 5, p. I005-12, 200 I.

12. KURATSU, S. Usefulness of argyrophilic nucleolar organizer 
staining for histologic grading of soft tissue sarcomas. J Surg Oncol, v. 54, p. 139-45, 1993.

13. KURATSU, S. Usefulness of argyrophilic nucleolar organizer staining for predicting prognosis of patients with recurrent soft tissue sarcoma. Oncology, v. 5I, n. 3, p. 244-50, 1994.

14. ÖFNER, D. et al. Wet autoclave pretreatment improves the visualisation of silver-stained nucleolar organizer region associated proteins (AgNORs) in routinely formalin-fixed and paraffin-embedded tissues. Mod Pathol, v. 7, p. 946-50, 1994.

15. ÖFNER, D. et al. Standardized staining and analysis of argyrophilic nucleolar organizer region associated proteins (AgNORs) in radically resected colorectal adenocarcinoma: correlation with tumour stage and long-term survival. J Pathol, v. I75, p. 44I -48, 1995.

16. OSHIMA, C.T.; FORONES, N. M.AgNOR in stomach neoplasm. Arq Gastroenterol, v. 38, n. 2, p. 89-93, 2001.
17. PARDUE, M.L.; GALL,J. G. Molecular hybridization of radioactive DNA to the DNA of cytological preparations. Proc NatlAcad Sci USA, v. 64, p. 600-4, 1969.

I8. PLOTON, D. et al. Improvement in the staining and in the visualisation of the argyrophilic proteins of the nucleolar organizer region at the optical level. Histochem J, v. 18, p. $5-14,1986$.

19. PLOTON, D. Behaviour of nucleolus during mitosis. Chromosoma, v. 95, p. 95- 107, 1987.

20. ROOSER, B. Prognostic factors in synovial sarcoma. Cancer, v. 63, n. II, p. $2182-5,1989$

21. RÜSCHOFF, J. et al. Prognostic significance of nucleolar organizing regions (NORs) in carcinomas of the sigmoid colon and rectum. Path Res Pract, v. I86, p. 85-91, 1990.

22. SKYTTING, B.T. Ki-67 is strongly prognostic in synovial sarcoma: analysis based on 86 patients from the Scandinavian Sarcoma group register. Br J Cancer, v. 80, n. I I, p. I809-14, 1999. 